KEYWORDS

Public investment

Physical infrastructure

Industry

Manufactures

Productivity

Costs

Econometric models

Colombia

Sergio Jiménez R.

Assistant Professor,

Department of Economics

University of Pamplona, Colombia

•sjimenez@unipamplona.edu.co

Jaime Sanaú V.

Professor of Applied Economics

Department of Economic History

and Applied Economics

University of Zaragoza, Spain

- jsanau@unizar.es
CEPAL REVIEW 104 - AUGUST 2011

\section{Colombia: public capital and manufacturing productivity}

$\mathrm{T}$

he work described in this article takes an approach based on duality theory to examine the impact of public infrastructures on manufacturing productivity in Colombia between 1990 and 2005. The effect on the manufacturing cost structure of public capital investment is analysed by means of the substitution or complementarity among the various factors of private production and public capital. 


\section{I}

\section{Introduction}

Economies need good quality transport, energy and hydraulic infrastructure in order to expand their domestic markets and compete on the international front. Economists first broached the idea that public investment in infrastructure (or public capital) helps to increase productivity several decades ago and a number of authors were writing on the subject as early as the 1950s.

During the final decades of the twentieth century, politicians and economists became increasingly anxious to establish why productivity growth had slowed in the United States in the 1970s after rising rapidly in the 1960s. This led to renewed research interest in the factors that drive productivity and economic growth and gave rise to a number of ground-breaking papers, including Aschauer (1989). In his work published in 1989, referring to the United States economy, Aschauer reported findings to the effect that public capital was an "important factor" in production, with an output elasticity of 0.39. A large body of literature followed this seminal work and produced extremely varied findings.

Many of the more recent studies based on Aschauer's results have found a perhaps more plausible output elasticity for public capital. Others have adopted different methodologies with as much (or even more) scientific endorsement, but have cast doubt on the hypothesis that public capital is such a strong driver of productivity gains as had been suggested by Aschauer's pioneering work-although they do not deny its importance.

Further research into the relationship between public infrastructure and manufacturing productivity is motivated by the fact that rather different results are obtained when two different methodologies - the production function and the dual cost function- are used.

Intuitively, it seems logical that roads, highways, ports, airports, water transport systems, sewerage systems and so forth provide a propitious setting for private production. This premise has been common currency in various branches of economic literature for decades,

$\square$ The authors wish to thank anonymous assessors for their suggestions and the editors of the CEPAL Review whose work undoubtedly added value to the article. The research was carried out by the Explanatory Factors in Economic Growth in Developed Countries (FECEPAD) group at the University of Zaragoza and funded by the Government of Aragon, the University of Zaragoza and the European Social Fund. but came into its own as a research topic in the late 1980s when Aschauer published his study contributing empirical evidence to the idea.

Aschauer was followed by other authors who conducted similar research for a number of industrialized countries, both nationwide and by regions or sectors of production, and from a variety of perspectives. Munnell (1990) and Sanaú (1998), among others, looked at the links between public capital and productivity using the production function and other authors adopted the dual cost function approach.

Most studies of this sort have focused on countries of the Organization for Economic Cooperation and Development (OECD), particularly Spain and the United States. Calderón and Servén (2010a and 2010b) examined the link between infrastructure endowment and growth and economic development processes in low- and middle-income countries, but little empirical evidence exists for these countries and still less for Colombia. Yet economic analysts in Latin America often agree that that the failings of public infrastructure in the region's countries constitute one of its greatest handicaps in terms of consolidating development and one of the main drags on its export competitiveness. This work seeks to contribute empirical evidence from a middle-income country on the link between public capital, productivity and economic growth more broadly.

Major institutional changes over the years in Colombia have ostensibly brought about greater macroeconomic stability and more robust aggregate production, as well as a considerable improvement in living standards. During the period covered in this study (not including the recession of 1998-1999), gross domestic product (GDP) expanded at an average annual rate of $3.7 \%$ in real terms and manufacturing exports rose by $14 \%$ per year on average. The share of manufacturing in total exports rose from $25 \%$ in 1990 to $35 \%$ in 2005 .

Infrastructure investment in Colombia received a boost in the 1990s from a substantial legislative change adopted in 1991 allowing private sector investment in infrastructure projects. Hitherto, infrastructure investment had been a monopoly of the State and therefore depended largely on the balance of the public accounts, whose frequently negative position placed constraints on such investment. 
Advances were made in infrastructure in Colombia after the 1991 legislative change, as rising participation by private enterprise more than offset a slight fall in public investment levels. The private sector began to account for a significant proportion of total investment in infrastructure in the years immediately following the new legislation, with an average of $28 \%$ between 1991 and 1994. Its share continued to increase thereafter, however, and reached 48\% in 1995-2004.

Generally speaking, between 1989 and 2004, total investment in infrastructure (whether publicly or privately financed) rose by an average of $9.2 \%$ per year, in theory providing conditions for the different sectors of the economy to increase productivity and growth.
This work is structured as follows. Section II introduces the theoretical model based on the duality theory; from this we derive expressions for the marginal contributions of public and private capital to the reduction of variable costs (i.e. shadow costs) and for output and cost elasticities with respect to both types of capital. We then describe the variables and data, as well as the process for estimating the public and private capital stock series and the econometric model used for empirical testing. The findings of this exercise are also compared with those of some of the major research works in the field. Lastly, we offer the main conclusions arising from the findings.

\section{II}

\section{Theoretical model, data and estimates}

\section{Theoretical model}

Duality theory, which employs a cost function to represent the returns on investment in infrastructure, offers a slightly different approach to the production function structure used in numerous other works. Morrison and Schwartz (1996) note that a useful characteristic of the cost function approach is its representation of behavioural response and technological linkages assuming that cost minimization is reasonable supposition.

Another asset of the cost function structure is that it produces demand factor equations with endogenous dependent variables, unlike estimation equations derived using the production function approach (very often the production function itself), in which the levels of the inputs are the arguments of the function.

The point of departure, following Boscá, Escribá and Dabán (1999) and Moreno, López-Bazo and Artís (2002), is a production function in which $Y$ represents output and $X_{i}(i=1, \ldots, s)$ is the $i$-th factor:

$$
Y=F\left(X_{1}, \ldots, X_{s}\right)
$$

It is supposed that firms must accept a price vector of the factors of production, $P_{1}, \ldots, P_{s}$, such that optimization lies in choosing the quantity of factors that minimize the cost of producing a given output level, $Y$. A set of demand functions for private factors may be obtained such that:

$$
X_{i}=X_{i}\left(P_{1}, \ldots, P_{s}, Y\right)
$$

where $X_{i}$ is the optimum quantity of the $i$-th factor. In this case, the optimum level of costs $(C)$ produces a cost function which is dual to the production function, since it depends on price factors and on output:

$$
C=C\left(P_{1}, \ldots, P_{s}, Y\right)
$$

It is assumed, then, that all the factors of production may be adjusted over a period of time, such that the firm can instantly determine long-term demand factors.

There are grounds for supposing that certain factors do not adjust instantly to their long-term equilibrium values, however, including investment costs, disinvestment and institutional constraints that lie outside the control of an individual firm in the short term. Accordingly, a distinction is drawn between production factors that are in equilibrium — variable inputs - and non-variable or fixed inputs. This set-up is known as "partial static equilibrium". In the structure adopted here, variable factors are distinguished from fixed factors. Businesses aim to minimize the cost of variable factors conditioned by a given stock of fixed factors.

Since one of the purposes of the empirical work is to obtain elasticities of public capital, the approach 
starts with an extended production function with public capital as an unpaid factor, and this must be taken into account in calculating the corresponding cost function. Accordingly, the variable cost function used treats public capital as an external fixed factor:

$$
C V=C V\left(P_{L}, P_{M}, Y, K_{P}, K_{G}\right)
$$

Equation (4) contains two variable private inputs: labour $(L)$ and intermediate materials $(M)$, which appear in the cost function represented by their prices, $P_{L}$ and $P_{M}$, respectively; a fixed factor: private capital, $K_{P}$; and $Y$ as production and $K_{G}$ as public capital, which acts as an external factor. Consequently, public infrastructure is treated as an unpaid fixed factor in the production process and one over which firms have almost no control.

The function of total short-term costs is the sum of the variable costs and the cost of existing private capital:

$$
C=C V(\cdot)+P_{K P} \cdot K_{P}
$$

where $P_{K P}$ is the cost of private capital.

The (short-term) effect of infrastructure investment on production occurs through firms' adjustment of their decisions with respect to the quantities of the different private variable inputs used in the production process. These decisions, in turn, depend on the degree to which these inputs are complemented or substituted by infrastructure following upgrading, given the existing quantity of fixed factors such as private capital.

Differentiating the variable cost function, $C V($.), from $K_{P}$, gives the shadow price, $Z_{K P}$, associated with private capital, which is defined as:

$$
Z_{K P} \equiv-\frac{\partial C V(\cdot)}{\partial K_{P}}
$$

The same procedure may be applied for public capital, $K_{G}$, to define its shadow price, $Z_{K G}$, as:

$$
Z_{K G} \equiv-\frac{\partial C V(\cdot)}{\partial K_{G}}
$$

Shadow prices reveal the marginal utility for firms associated with an increase in the public and private capital stock. They offer a measure of businesses' implicit short-term willingness to pay for private or public capital. Specifically, they are defined as the reduction in variable costs arising from a marginal increase in the stock of public or private capital. As long as a shadow price remains in positive territory, firms benefit from the additional infrastructure inasmuch as it allows them to achieve savings in their variable costs. ${ }^{1}$

Supposing that the prices of variable factors are exogenous to producers, Shephard's lemma may be applied to derive the vector of the cost-minimizing variable factors, i.e. cost-minimizing demands: ${ }^{2}$

$$
X_{i}=X_{i}\left(P_{L}, P_{M}, Y, K_{P}, K_{G}\right)=\frac{\partial C V}{\partial P_{i}} \quad i=L, M
$$

The cost-minimizing conditional factor demand functions may take the following specific form:

$$
\begin{gathered}
L\left(P_{L}, P_{M}, Y, K_{P}, K_{G}\right)=\frac{\partial C V(\cdot)}{\partial P_{L}} \\
M\left(P_{L}, P_{M}, Y, K_{P}, K_{G}\right)=\frac{\partial C V(\cdot)}{\partial P_{M}}
\end{gathered}
$$

Based on the conditional factor demand functions, we may rewrite the variable cost function as:

$$
C V\left(P_{L}, P_{M}, Y, K_{P}, K_{G}\right)=P_{L} L(\cdot)+P_{M} M(\cdot)
$$

Equation (9) is useful for determining the degree of complementarity or substitution between each fixed factor included in the calculation and each of the variable factors. From $(6 a)$ and $(6 b)$ it follows that the shadow prices of $K_{P}$ and $K_{G}$ are given by:

\footnotetext{
1 In this case the only requirement is a positive shadow price, since the structure proposed here assumes that firms do not pay for public capital, which is treated as an exogenous factor. However, although firms do not directly perceive the costs of public capital accumulation, they pay for infrastructure indirectly through taxation. Nevertheless, since taxes are not directly related to the costs incurred by the government in augmenting the capital stock, the price may be considered nil for the firm. This is the approach usually taken in preceding work and has therefore been adopted for this calculation too.

2 Shephard's lemma is used to generate cost-minimizing demand functions. Accordingly, it may be used to generate as many equations additional to the cost function as productive factors are involved in the production process. Estimating the system of cost function and of derived factor demand leads to more efficient parameter coefficients than could be obtained from a calculation based solely on cost function.
} 


$$
\begin{aligned}
& Z_{K P} \equiv-\frac{\partial C V}{\partial K_{P}}=-P_{L} \frac{\partial L(\cdot)}{K_{P}}-P_{M} \frac{\partial M(\cdot)}{\partial K_{P}}=L_{K P}+M_{K P} \\
& Z_{K G} \equiv-\frac{\partial C V}{\partial K_{G}}=-P_{L} \frac{\partial L(\cdot)}{\partial K_{G}}-P_{M} \frac{\partial M(\cdot)}{\partial K_{G}}=L_{K G}+M_{K G}
\end{aligned}
$$

The shadow prices are broken down into the effect on costs of an increase in $K_{P}$ and $K_{G}$, and the adjustment effects on labour and on intermediate expenditure. If $L_{K P}$ $\left(M_{K P}\right)$ is less than 0, labour (intermediate expenditure $(\mathrm{s})$ ) is (are) complementary to private capital. If $L_{K P}\left(M_{K P}\right)$ is greater than 0 , then intermediate expenditure(s)) on labour substitute for private capital. These same conclusions are valid, as well, for public capital.

We may also define each share of the factor $\left(S_{i}\right)$, i.e. the percentage of the presumed cost by the $i$-th factor:

$$
S_{i}=\frac{P_{i} \cdot X_{i}}{C V}=\frac{\partial \ln C V}{\partial \ln P_{i}}=\frac{\partial C V}{\partial P_{i}} \frac{P_{i}}{C V} \quad i=L, M
$$

The set of equations (4) and (11) constitute the solution to what may be defined as the short-term equilibrium relating to the variable factors. Demand functions may also be used, in which case the set of equations would be (4) and (8).

Next, we define a number of total cost elasticities in relation to the variable factors. First, elasticity is calculated with respect to private capital. Since firms pay for private capital, cost elasticity includes the price effect, such that:

$$
\varepsilon_{C K_{P}}=\frac{\partial \ln C}{\partial \ln K_{P}}=\left(P_{K_{P}}-Z_{K_{P}}\right) \frac{K_{P}}{C}
$$

When $K_{p}=K_{p}{ }^{*}$, it is because $P_{K p}=Z_{K p}$, so $\varepsilon C K_{p}=0$. However, outside stationary equilibrium, i.e. where firms cannot adjust $K_{p}$ instantly, $\varepsilon \mathrm{CKp} \neq 0$.

Second, since the purpose here is to assess the change in total short-term costs associated with a marginal rise in the infrastructure stock, short-term cost elasticity must be calculated with respect to public capital:

$$
\varepsilon_{C K_{G}}=\frac{\partial \ln C}{\partial \ln K_{G}}=\frac{\partial C}{\partial K_{G}} \frac{K_{G}}{C}=\frac{\partial C V}{\partial K_{G}} \frac{K_{G}}{C}
$$

The elasticity of variable costs with respect to public capital may be obtained from (13) and $(6 a, 6 b)$ :

$$
Z_{K_{G}} \equiv-\frac{\partial C V}{\partial K_{G}}=-\varepsilon_{C V K_{G}}\left(\frac{C V}{K_{G}}\right)
$$

from which we derive that: ${ }^{3}$

$$
\varepsilon_{C V K_{G}}=\frac{\partial \ln C V}{\partial \ln K_{G}}=\frac{\partial C V}{\partial K_{G}} \frac{K_{G}}{C V}
$$

Since firms do not pay directly for infrastructure, we may affirm that $\varepsilon_{C K_{G}}=-Z_{K_{G}}\left(\frac{K_{G}}{C}\right)$, such that the sole condition that must be satisfied for the investment in public capital to generate a positive effect on production is that $Z_{K_{G}}>0$. If $Z_{K_{G}}>0$, then $\varepsilon C K_{G}<0$. This will occur to the extent that public capital acts as a substitute for variable factors, i.e. as long as public infrastructures increase efficiency by reducing the usage of variable inputs and, thus, variable costs.

We may affirm that businesses will adjust their production decisions with respect to their own variable factors depending on the way these factors relate to public capital. This effect may be calculated as the (short-term) elasticity of conditional variable factor demand with respect to infrastructure:

$$
\varepsilon_{X_{i} K_{G}}=\frac{\partial \ln X_{i}}{\partial \ln K_{G}}=\frac{\partial X_{i}}{\partial K_{G}} \frac{K_{G}}{X_{i}} \quad i=L, M
$$

Some of the variables defined on the basis of cost function are found to be closely related to the usual measures of production function elasticities. Using the expressions derived above, output elasticities with respect to capital stock may be related to the shadow shares of those factors in total cost. Output elasticities with respect to fixed factors may be obtained from (6) and (11):

\footnotetext{
3 In formulating the model it is assumed that public infrastructures affect efficiency through changes in the use of variable inputs (quantity effect). Price effects, which are not considered in this article, also arise, however, inasmuch as broader or upgraded transport infrastructure may lower the cost of firms' intermediate inputs. Nevertheless, this effect may also cheapen and facilitate imports, limiting the market power of local manufacturers and eroding their products' sale prices.
} 


$$
\begin{gathered}
\varepsilon_{Y, K P} \equiv \frac{\partial \ln Y}{\partial \ln K_{P}}=\frac{\partial Y}{\partial K_{P}} \cdot \frac{K_{P}}{Y}=\frac{\partial Y}{\partial C} \cdot \frac{\partial C}{\partial K_{P}} \cdot \frac{K_{P}}{Y}= \\
=\frac{1}{C M a} \cdot Z_{K P} \cdot \frac{K_{P}}{Y} \equiv \frac{S_{K P}^{*}}{\varepsilon_{C, Y}} \\
\varepsilon_{Y, K G} \equiv \frac{\partial \ln Y}{\partial \ln K_{G}}=\frac{\partial Y}{\partial K_{G}} \cdot \frac{K_{G}}{Y}=\frac{\partial Y}{\partial C} \cdot \frac{\partial C}{\partial K_{G}} \cdot \frac{K_{G}}{Y}= \\
=\frac{1}{C M a} \cdot Z_{K G} \cdot \frac{K_{G}}{Y} \equiv \frac{S_{K G}^{*}}{\varepsilon_{C, Y}}
\end{gathered}
$$

where

$$
\varepsilon_{C, Y} \equiv \frac{\partial \ln C}{\partial \ln Y}=\frac{\partial C}{\partial Y} \cdot \frac{Y}{C}=\frac{C M a}{C / Y}
$$

showing that the ratio between marginal cost and average cost determines cost elasticity in relation to short-term output, $\varepsilon_{C, Y}$, which is related in turn to the elasticity of variable costs with respect to output, $\varepsilon_{C V, Y}$.

\section{Data}

Much of the statistical information used for the variables of the model is compiled and published by the National Administrative Department of Statistics (DANE), the government body responsible for statistics in Colombia. However, we will also describe the process used for estimating two of the basic components for this study: private capital stock and public capital stock. These variables are not calculated by DANE and had not previously been estimated for Colombia for the study period covered here.

For empirical testing we used annual data on prices and quantities of factors and production for the different sectors of Colombia's manufacturing industry for 19902005, which were compiled from several sources. This is the only period for which full information is available on all the necessary variables. Accordingly, the empirical analysis could not be conducted for more recent years, since although statistical information on the variables relating to manufacturing activity levels is updated to 2007, data on infrastructure investment, which is essential for the analysis, are available only up to 2005 .

Data on production, consumption of intermediate inputs, number of workers and wages in the manufacturing sectors were obtained from the Annual Manufacturing Survey, which is produced and published by DANE.
Data on gross fixed capital formation (GFCF) come from Colombia's national accounts (DANE) and data on investment in infrastructure used to build the private capital stock and the public capital stock were taken from the Infrastructure and Sustainable Energy Division of the National Planning Department. All the data in monetary quantities are expressed in Colombian pesos at constant 1994 prices.

With respect to the period 1990-2000, the data originally disaggregated for 29 manufacturing subsectors, then revised as of 2001 in line with the International Standard Industrial Classification of All Economic Activities (ISIC Rev. 3) for 67 industrial classifications, were finally grouped in 12 major sectors, following Nadiri and Mamuneas (1994). Annex I shows the sectoral classification employed, which must naturally be borne in mind when interpreting the results. ${ }^{4}$

Several authors, including Nadiri and Mamuneas (1994), Boscá, Escribá and Dabán (1999), and Moreno, López-Bazo and Artís (2002), measure each sector's output by the value of gross manufacturing production at constant prices. The value of gross production is defined as the sum of gross value added (GVA) and expenditures on intermediate inputs. Intermediate inputs are quantified, in turn, as the value of firms' intermediate consumption (materials, energy and services purchased). The labour factor is measured as the number of employees (workers and administrative staff) in each sector. No alternative measures for labour, such as hours worked, or data on human capital were available.

The price index for intermediate inputs was obtained for all the years covered by the implicit price index of total supply and demand from the national accounts published by DANE. The price of labour is wage per worker, taken from the Annual Manufacturing Survey conducted by DANE. Wages per worker are calculated as the ratio between gross wages and the number of workers, divided by the GDP implicit price deflator. The price of private capital, or the rental rate of capital, is calculated -following Moreno, López-Bazo and Artís (2002)as $P_{K P}=q(r+d)$, where $q$ is the implicit price index of GFCF taken from the national accounts published by DANE, $r$ is the bank lending rate taken from the historical

\footnotetext{
4 In 2005, for example, the sectors "Food products, beverages and tobacco", "Chemicals and chemical products", "Refined petroleum, fuels and petroleum derivatives" (which tripled its invoicing between 1990 and 2005) and "Common metals and basic metallic products" represented almost two thirds of manufacturing production. Conversely, "Machinery and electrical, electronic and scientific equipment", "General-purpose machinery" and "Wood and products of wood and cork" represented less than $2 \%$ each.
} 
statistics of the National Planning Department and $d$ is the rate of private capital depreciation taken from Mas, Pérez and Uriel (2005). ${ }^{5}$

Both public and private capital were measured as total net stock at year-end and, since no valuations exist for those stocks in Colombia, both were estimated. More recent literature has tended to estimate and use capital services, however, rather than net capital stock, as in OECD (2001), Mas, Pérez and Uriel (2005), and Schreyer and Dupont (2006), for example.

Schreyer and Dupont (2006) argue that two dimensions must be distinguished in the measurement of capital. Net capital stocks and changes therein are useful for measuring capital as a store of wealth, whereas productive stock and its rate of variation, i.e. the flow of capital services, is more suitable for measuring capital as a factor of production. According to these authors, the quantity of capital services — not net capital stock - is conceptually the correct measurement for analysing productivity and production. However, it was not possible to use capital services flow figures, because the statistical data needed to construct and estimate those series for Colombia far exceed the amount of reliable statistical information available.

Accordingly, given these information constraints, the most viable option was to estimate the net capital stock and work with those series. Net endowments of public and private capital were estimated using a function which accumulates GFCF in the first case and investment in infrastructure in the second, discounting part of investments made in the past for depreciation. The system used was the permanent inventory method, which starts with an initial stock, adds annual spending on gross investment and deducts imputed depreciation. This method was employed recently in the EU KLEMS Project carried out to examine technology stocks. ${ }^{6}$

Private capital was estimated on the basis of the series which disaggregate GFCF by fixed assets invested for each of the 12 branches of manufacturing examined (data obtained from the DANE annual survey). The permanent inventory method was applied to these series expressed in Colombian pesos at constant 1994 prices, to obtain the private capital stock for each of the 12

\footnotetext{
5 An alternative source in this case would be to use data on the cost of private capital utilization. Data on the cost of capital usage index employed in Botero, Hassan and Palacio (2007) for Colombia were also tried here, but this produced no major differences in the findings compared to those obtained using the rental rate of private capital.

6 See O'Mahony and others (2008) for a description of sources and methods used for estimating technology stocks, published in: www. euklems.net.
}

branches of manufacturing, using a procedure similar to that employed for infrastructure endowments, as described below.

Public capital stock was estimated using annual data on public and private investment in infrastructure issued by the National Planning Department. ${ }^{7}$ In keeping with the empirical literature on the subject, public capital stock enters the model with a year's lag, on the basis that the infrastructure completed in any given year begins to have a consistent impact on manufacturing activity the following year.

The formula applied is based on the proposal by Soete and Patel (1985), that $K G_{t}=\sum \theta_{i} \cdot I N V_{t-1}$, where $K G_{t}$ is the capital stock in the period $t ; \theta_{i}$ refers to the lag with which public or private investment in capital augments the stock and also captures the rate of depreciation of physical capital; and $I N V_{t-1}$ is GFCF (or investment in infrastructure) in the period prior to $t$. The rates of depreciation employed to estimate the two types of stocks correspond to the annual rate of fixed capital consumption used by Mas, Pérez and Uriel (2005) to calculate public and private capital stocks in Spain. ${ }^{8}$

Thus, following the permanent inventory method, the initial capital stock $K G$ was calculated as:

$$
\left.\begin{array}{c}
K G_{i, t+i}=I N V_{i, t+1-\theta}+(1-\delta) K G_{i, t} \\
K G_{i, t+1}=\left(1+g_{i}\right) \cdot K G_{i, t} \\
I N V_{i, t+1-\theta}+(1-\delta) K G_{i, t}= \\
\left(1+g_{i}\right) \cdot K G_{i, t} \Rightarrow I N V_{i, t+1-\theta}= \\
{\left[1+g_{i}-(1-\delta)\right] K G_{i, t}}
\end{array}\right\}
$$

from which we obtain $K G_{i, t}=\frac{I N V_{i, t+1-\theta}}{g_{i}+\delta}$, where $t$ is the initial period $K G_{i, t}$; is the initial capital stock; $\theta$ is the lag structure (the average lag between the materialization of the investment and the derivation of its effects), which reduces possible simultaneity biases; $g_{i}$ is the cumulative average annual rate of growth of GFCF of sector $i$ during a particular period; and $\delta$ is the rate of depreciation of the previous year's capital stock. Here, the formula for calculating the initial stock for sector $i$, i.e. for 1990 , would be as follows:

\footnotetext{
7 Investment in public infrastructure spans four categories: telecommunications, transport, energy and hydraulics.

8 The outcomes were found to vary very little using higher or slightly lower depreciation rates than those used by Mas, Pérez and Uriel (2005).
} 


$$
K G_{i, 90}=\frac{I N V_{i, t+1-2}}{g_{i}+\delta}=\frac{I N V_{i, 89}}{g_{i}+\delta}
$$

\section{Estimating the cost function}

Since the main objective is to test the impact of public capital endowments on the costs of Colombian manufacturing firms, the empirical work performed here was based on a Leontief generalized cost function, in the form shown in equation (20), which takes into account the theoretical propositions discussed in subsection 1.

In this case we use a time trend $t$ to capture technological change, which has also been employed, for example, by Morrison and Schwartz (1996)..$^{9}$ This functional form makes it possible to consider a large number of possibilities for substitution between factors, as well as the existence of fixed short-term factors, and it may be adapted for any production technology without the need to impose restrictions a priori on returns to scale.

Bearing in mind the variable inputs, labour $(L)$ and intermediate consumption $(M)$, the Leontief generalized cost function, composed basically of three equations, may take the following form:

- Variable cost function:

$$
\begin{gathered}
C V=Y\left[\sum_{i} \sum_{j} \alpha_{i j} P_{i}^{1 / 2} P_{j}^{1 / 2}+\sum_{i} \sum_{m} \delta_{i m} P_{i} s_{m}^{1 / 2}+\right. \\
\left.\sum_{i} P_{i} \sum_{m} \sum_{n} \gamma_{m n} s_{m}^{1 / 2} s_{n}^{1 / 2}\right]+ \\
Y^{1 / 2}\left[\sum_{i} \sum_{k} \delta_{i k} P_{i} x_{k}^{1 / 2}+\sum_{i} P_{i} \sum_{m} \sum_{k} \gamma_{m k} s_{m}^{1 / 2} x_{k}^{1 / 2}\right]+ \\
\sum_{i} P_{i} \sum_{k} \sum_{k g} \gamma_{k k g} x_{k}^{1 / 2} x_{k g}^{1 / 2}
\end{gathered}
$$

where $P_{i}$ and $P_{j}$ are the prices of the variable factors; $X_{i} ; x_{k}$ y $x_{k g}$ are the fixed factors; and $s_{m}$ and $s_{n}$ are the rest of the arguments (for example, production $Y$, and time $t$ ).

9 There are no series on research and development (R\&D) or for technological capital stock in the Colombian economy for the period studied.
- Variable demand factor equations (one for each factor):

$$
\begin{gathered}
\frac{X_{i}}{Y}=\frac{\partial C V}{\partial P_{i}} \frac{1}{Y}=\sum_{i} \alpha_{i j}\left(P_{j} / P_{i}\right)^{1 / 2}+ \\
\sum_{m} \delta_{i m} s_{m}^{1 / 2}+\sum_{m} \sum_{n} \gamma_{m n} s_{m}^{1 / 2} s_{n}^{1 / 2}+ \\
Y^{-1 / 2}\left[\sum_{k} \delta_{i k} x_{k}^{1 / 2}+\sum_{m} \sum_{k} \gamma_{m k} s_{m}^{1 / 2} x_{k}^{1 / 2}\right]+ \\
Y^{-1} \sum_{k} \sum_{k g} \gamma_{k k g} x_{k}^{1 / 2} x_{k g}^{1 / 2}
\end{gathered}
$$

The two variable input demand equations are obtained by applying Shephard's lemma to the variable cost function, and are expressed as input-output equations so as to correct for heteroskedasticity problems upon empirical testing of the model.

To complete the system formed by the three equations, Morrison and Schwartz (1996) and Boscá, Escribá and Dabán (1999) add another expression to represent short-term utility-maximizing behaviour. This equation represents the equalizing condition between output price $(P)$ and short-term marginal cost $(C M a)$. This condition is not imposed and is estimated simply as another equation in the system.

- Price and marginal cost equalization equation:

$$
\begin{gathered}
P=C M a=\frac{\partial C V}{\partial Y}=\sum_{i} \sum_{j} \alpha_{i j} P_{i}^{1 / 2} P_{j}^{1 / 2}+ \\
\sum_{i} \sum_{m} \delta_{i m} P_{i} s_{m}^{1 / 2}+\sum_{i} P_{i} \sum_{m} \sum_{n} \gamma_{m n} s_{m}^{1 / 2} s_{n}^{1 / 2}+ \\
1 / 2 Y^{-1 / 2}\left[\sum_{i} \sum_{k} \delta_{i k} P_{i} x_{k}^{1 / 2}+\sum_{i} P_{i} \sum_{m} \sum_{k} \gamma_{m k} s_{m}^{1 / 2} x_{k}^{1 / 2}\right]+ \\
1 / 2 Y^{1 / 2} \sum_{i} \delta_{i Y} P_{i}+Y^{1 / 2}\left[\sum_{i} P_{i} \sum_{m} \gamma_{m Y} s_{m}^{1 / 2}\right]+ \\
1 / 2 \sum_{i} P_{i} \sum_{k} \gamma_{Y k} x_{k}^{1 / 2}
\end{gathered}
$$

We may thus proceed to estimate this four-equation system in order to obtain the relevant cost function parameters. These are then used to calculate the shadow prices and elasticities which will provide a basis on which to analyse the impacts of infrastructure and private capital on the productivity of the different branches of manufacturing, as set forth below.

\section{Findings}

Since the results derived from the separate regression exercises are not statistically equivalent to those obtained 
when the estimates are performed using a system of equations, the regression method employed was the system of seemingly unrelated regression equations (SURE), which confers structure and robustness and makes the estimators more efficient (higher $t$-statistics). This method allows us to impose equality restrictions between parameters by means of equations to adjust them to the theoretical models. ${ }^{10}$

Equations (22), (23) and (24) were estimated using the SURE method, employing the STATA econometric software. The cost equation estimated in the specification finally chosen was average variable costs $(C V / Y)$, however, since this corrects possible heteroskedasticity problems in the model which can arise when, as occurs in this work,

10 An ambitious public investment programme exerts short-term demand effects which may be quantified using various methodologies, including the Leontief generalized cost function within the input-output framework. These are not the effects examined in this work, however, which estimates the supply-side effects generated once the infrastructure is operational. Before performing these estimates a Granger causality test was run to allow rejection, on the one hand, of the nil hypothesis that infrastructure has no causal relationship with either output or the variable costs of the 12 major groups in Colombian manufacturing. On the other hand, the test did not rule out the possibility that output or variable costs in those sectors cause infrastructure, in the sense of Granger causality. It was concluded that the direction of causality was that determined by the model. we consider together individual firms whose explanatory variables can vary considerably in value.

Table 1 shows the results of the estimation, giving the values obtained for each of the parameters and $t$-statistics. Owing to the complexity of the Leontief generalized cost function, we cannot interpret the sign and magnitude of the coefficients directly. It may be observed, however, that most of the parameters are statistically significant at the usual levels. Also, the four equations estimated generally show a good level of adjustment. In interpreting the results, it must be recalled that firms are grouped in one of the 12 major sectors of activity examined according to the criteria employed by DANE, and that these are very different in nature and account for very different shares in Colombia's overall manufacturing production.

Tables 2 and 3 summarize some of the most important effects of investment in private capital and infrastructure. Specifically, those relating to the shadow values of the two types of capital and substitution or complementarity (or both) existing between each type of capital and each of the variable inputs (see table 2). Table 3 shows the effects on the elasticities of output and of total short-term costs with respect to public and private capital. All these effects were calculated for each of the 12 manufacturing groups, as average values for

TABLE 1

Estimated coefficients. Leontief generalized cost function

\begin{tabular}{|c|c|c|c|c|c|}
\hline Parameter & Coefficient & $t$-statistic & Parameter & Coefficient & $t$-statistic \\
\hline$\alpha_{P L P L}$ & -0.149134000 & -5.05 & $\delta_{P M K G}$ & -0.024718500 & -2.20 \\
\hline$\alpha_{P M P M}$ & 0.254143300 & 2.89 & $\gamma_{P L Y K P}$ & -0.000022600 & -1.61 \\
\hline$\alpha_{P L P M}$ & 0.077230900 & 10.07 & $\gamma_{P L Y K G}$ & -0.000001100 & -0.22 \\
\hline$\delta_{P L Y}$ & 0.000054300 & 2.82 & $\gamma_{P L T K P}$ & 0.004589800 & 0.88 \\
\hline$\delta_{P M Y}$ & -0.000100500 & -2.29 & $\gamma_{P L T K G}$ & -0.002259400 & -2.11 \\
\hline$\delta_{P L T}$ & -0.003830200 & -0.43 & $\gamma_{P M Y K P}$ & 0.000064200 & 2.17 \\
\hline$\delta_{P M T}$ & 0.078250300 & 3.00 & $\gamma_{P M Y K G}$ & -0.000048000 & -3.89 \\
\hline$\gamma_{P L Y Y}$ & -0.000000007 & -1.83 & $\gamma_{P M T K P}$ & 0.029168300 & 2.39 \\
\hline$\gamma_{P L Y T}$ & 0.000000691 & 0.36 & $\gamma_{P M T K G}$ & 0.002838700 & 1.06 \\
\hline$\gamma_{P L T T}$ & -0.003612300 & -1.83 & $\gamma_{P L K P K G}$ & -0.003545400 & -2.19 \\
\hline$\gamma_{P M Y Y}$ & 0.000000011 & 1.47 & $\gamma_{P L K P K P}$ & -0.011634600 & -1.94 \\
\hline$\gamma_{P M Y T}$ & -0.000001340 & -0.35 & $\gamma_{P L K G K G}$ & -0.000110400 & -0.32 \\
\hline$\gamma_{P M T T}$ & -0.003969500 & -1.00 & $\gamma_{P M K P K G}$ & 0.013560900 & 3.83 \\
\hline$\delta_{P L K P}$ & 0.084150700 & 3.28 & $\gamma_{P M K P K P}$ & -0.030954500 & -2.27 \\
\hline$\delta_{P L K G}$ & 0.021917900 & 4.39 & $\gamma_{P M K G K G}$ & -0.001359800 & -1.90 \\
\hline$\delta_{P M K P}$ & -0.303561200 & -4.82 & & & \\
\hline
\end{tabular}

Average variable cost function: $\mathrm{R}^{2}=0.3537$

Labour demand function: $\mathrm{R}^{2}=0.8688$

Intermediate consumption demand function: $\mathrm{R}^{2}=0.3478$

Price and marginal cost equalizing equation: $\mathrm{R}^{2}=0.9979$

Source: prepared by the authors.

Note: sample period 1990-2005. Twelve sectors of manufacturing. Number of observations: 192. 
TABLE 2

Shadow prices and substitution or complementarity. Sector averages

\begin{tabular}{|c|c|c|c|c|c|c|}
\hline & $Z_{K G}$ & $Z_{K P}$ & $L_{K G}$ & $M_{K G}$ & $L_{K P}$ & $M_{K P}$ \\
\hline Food products, beverages and tobacco & 0.0594 & 0.0364 & -0.0058 & 0.0651 & 0.0087 & 0.0276 \\
\hline Textiles, textile products, leather and footwear & 0.0162 & 0.0546 & -0.0018 & 0.0179 & -0.0053 & 0.0599 \\
\hline Wood and products of wood and cork & 0.0027 & -0.0068 & -0.0006 & 0.0033 & 0.0112 & -0.0179 \\
\hline Pulp, paper, paper products, printing and publishing & 0.0109 & 0.0484 & -0.0024 & 0.0133 & -0.0135 & 0.0619 \\
\hline Coke, refined petroleum products and nuclear fuel & 0.0104 & 0.0260 & -0.0047 & 0.0151 & -0.0323 & 0.0583 \\
\hline Chemicals and chemical products & 0.0215 & 0.0356 & -0.0059 & 0.0274 & -0.0240 & 0.0596 \\
\hline Rubber and plastic products & 0.0070 & 0.0450 & -0.0018 & 0.0088 & -0.0113 & 0.0563 \\
\hline Other non-metallic mineral products & 0.0070 & 0.0580 & -0.0007 & 0.0077 & 0.0010 & 0.0570 \\
\hline Basic metals and fabricated metal products & 0.0112 & 0.0522 & -0.0017 & 0.0130 & -0.0077 & 0.0599 \\
\hline Machinery and equipment, n.e.c. & 0.0036 & -0.0055 & -0.0014 & 0.0050 & -0.0096 & 0.0041 \\
\hline Electrical and optical equipment & 0.0033 & 0.0267 & -0.0014 & 0.0047 & -0.0014 & 0.0281 \\
\hline Transport equipment & 0.0072 & -0.0005 & -0.0036 & 0.0108 & -0.0474 & 0.0469 \\
\hline Overall average & 0.0134 & 0.0309 & -0.0026 & 0.0160 & -0.0110 & 0.0418 \\
\hline
\end{tabular}

Source: prepared by the authors.

Note: $Z_{K G}$ is the shadow price of public capital; $Z_{K P}$ is the shadow price of private capital; $L_{K G}$ is the direct effect of public capital on employment; $M_{K G}$ is the direct effect of public capital on intermediate inputs; $L_{K P}$ is the direct effect of private capital on employment, and $M_{K P}$ is the direct effect of private capital on intermediate inputs.

TABLE 3

Output and cost elasticity with respect to public and private capital. Sector averages

\begin{tabular}{lcccc}
\hline & & & & $\varepsilon_{C, K G}$ \\
\hline Food products, beverages and tobacco & $\varepsilon_{Y, K G}$ & $\varepsilon_{Y, K P}$ & $\varepsilon_{C, K P}$ \\
Textiles, textile products, leather and footwear & 0.0576 & 0.0175 & -0.1792 & 0.3737 \\
Wood and products of wood and cork & 0.0902 & 0.0787 & -0.1276 & 0.4869 \\
Pulp, paper, paper products, printing and publishing & 0.3092 & 0.1013 & -0.2035 & 0.5194 \\
Coke, refined petroleum products and nuclear fuel & 0.0824 & 0.0709 & -0.1213 & 0.4709 \\
Chemicals and chemical products & -0.0349 & 0.0376 & -0.1371 & 0.4551 \\
Rubber and plastic products & 0.0646 & 0.0223 & -0.1607 & 0.4240 \\
Other non-metallic mineral products & 0.0947 & 0.0835 & -0.1200 & 0.4592 \\
Basic metals and fabricated metal products & 0.0870 & 0.1913 & -0.0813 & 0.6151 \\
Machinery and equipment, n.e.c. & 0.0908 & 0.0955 & -0.1189 & 0.4917 \\
Electrical and optical equipment & 0.2104 & 0.0184 & -0.2200 & 0.4029 \\
Transport equipment & 0.1386 & 0.0925 & -0.1193 & 0.5231 \\
& 0.1105 & 0.0065 & -0.1935 & 0.2976 \\
Overall average & & & \\
\hline
\end{tabular}

Source: prepared by the authors.

Note: $\varepsilon_{Y, K G}$ is output elasticity with respect to public capital; $\varepsilon_{Y, K P}$ is output elasticity with respect to private capital $\varepsilon_{C, K G}$ is cost elasticity with respect to public capital; and $\varepsilon_{C, K P}$ is cost elasticity with respect to private capital. 
the period 1990-2005 weighted by the magnitude of each sector. ${ }^{11}$

It will be recalled that the duality approach was adopted to overcome one of the main limitations occurring in analysis of the impacts of public capital on economic development by using production functions (mainly of the Cobb-Douglas type), i.e. by imposing strict "substitutability" among the factors of production and treating all the factors as variable. Once this obstacle is overcome, it is valid to discuss relations between the shadow prices of fixed factors and their utilization cost, as will be done later.

The first two columns of table 2 show those shadow prices with average values for the 16 years of the sample for each of the 12 manufacturing sectors. The shadow price of public capital, $Z_{K G}$, is positive in all the manufacturing sectors examined and for every year of the sample, with an average value of 0.0134 , albeit with notable differences: from 0.0027 for "Wood and products of wood and cork" to 0.0594 for "Food products, beverages and tobacco". ${ }^{12}$

The fact that the shadow price of public capital stock is positive for all sectors and years reflects the marginal utility experienced by the manufacturing industry from public capital investments. It also shows the marginal contribution to the reduction in variable costs in Colombia's manufacturing sector, inasmuch as the magnitude of the shadow price represents the willingness of private industry to pay for additional units of public capital.

This implicit willingness of private industry to pay for infrastructure in the short term across all sectors implies a relation of net substitution between public capital stock and the variable production factors considered in the model (labour and intermediate consumption) during the period examined. The positive value of the shadow price may also be interpreted as showing that firms save

approximately 1.34 cents in variable costs for every

\footnotetext{
11 We also calculated these outcomes for each of the 16 years of the period studied and the average values for the set of 12 manufacturing sectors. The resulting coefficients showed that the shadow price of public capital tended to grow in magnitude over the 16 years, which may indicate that the mismatch between infrastructure and manufacturing activity increased in this period. The tables of results are available from the authors upon request.

12 Wide variance in the shadow price of public capital between sample individuals is documented in other works too. Boscá, Escribá and Dabán (1999), for example, obtained very uneven results, with shadow prices varying from -0.077 in Extremadura (the Spanish region with the lower per capita GDP) to 0.229 in the Basque Region (the region with the highest per capita GDP).
}

additional Colombian peso (the country's monetary unit) invested in infrastructure.

As may be expected (and hence the interest in analysing the manufacturing sector at a disaggregated level), shadow prices behaved fairly unevenly, although always positively, across different sectors of manufacturing, indicating that some sectors enjoy greater marginal impacts from public capital investment.

The greatest impact was registered in the sector "Food products, beverages and tobacco", followed at a considerable distance by "Chemicals and chemical products", "Textiles, textile products, leather and footwear" and "Basic metals and fabricated metal products". These findings are even more significant in view of the fact that in recent years these four sectors have been the largest in Colombian manufacturing, in terms of contribution to GDP and workers employed. The outcomes for the shadow price of public capital have economic policy implications for improving the performance of the Colombian economy and boosting growth in manufacturing GDP.

The links between investment in public capital and employment will be seen more clearly later, in the discussion on elasticity of substitution (or complementarity) between public capital and the two variable factors included in the model (labour and intermediate consumption).

The manufacturing groupings whose variable costs were reduced least by investment in physical capital were "Wood and products of wood and cork", "Machinery and equipment, n.e.c." and "Electrical and optical equipment". The considerable variation in the value of shadow prices highlights the importance of disaggregated analysis of manufacturing, since not all sectors obtain the same benefits from investment in infrastructure.

In turn, the shadow prices of private capital, $Z_{K P}$, show an uneven pattern between sectors and over the years, unlike public capital shadow prices. Overall average values differ considerably too, and the shadow price of private capital is more than double that of public capital (see table 2).

Interestingly, private capital shadow prices follow a pattern similar to that of interest rates in Colombia. Throughout the 1990s, Colombian businesses had to contend with the highest interest rates in the country's recent history: over 40\% per annum between 1994 and 1998, in which year they peaked. This situation pushed up the cost of capital utilization enormously, making investment in fixed capital very burdensome and unbalancing firms' cost structures.

In the sectoral analysis of $Z_{K P}$, the largest positive 
impacts were registered in "Textiles, textile products, leather and footwear", "Other non-metallic mineral products" and "Basic metals and fabricated metal products". Conversely, "Wood and products of wood and cork", "Machinery and equipment, n.e.c." and "Transport equipment" recorded, on average, the smallest marginal contributions to variable cost reduction as a result of investment in physical capital.

Table 2 shows another important perspective on the findings: a breakdown of the shadow price, $Z_{K G}$, into the direct impact of public capital on employment-related costs, $L_{K G}$, and the costs associated with intermediate inputs, $M_{K G}$, i.e. the possible saving or additional utilization of each of the two variable factors. As shown in the two middle columns in table 2, public capital complemented labour and substituted intermediate consumption in the 12 sectors during the 16 years examined here, with average values of -0.003 and 0.016 , respectively. ${ }^{13}$

In other words, an increase in the public capital stock gave rise to higher labour costs but reduced costs associated with use of intermediate materials. More detailed examination of the two figures above shows that the variable cost reduction in the form of saving in intermediate consumption exerted a much larger influence (six times greater) than the variable cost increase produced by greater utilization of labour. The overall result of this is that the direction - and hence the predominant relationship between public capital and variable production factors - is one of substitution, i.e. the same result obtained in the analysis of shadow price, except that here we know the origin of the effect.

In the analysis by sector of production, "Food products, beverages and tobacco", "Coke, refined petroleum products and nuclear fuel" and "Chemicals and chemical products" showed the greatest complementarity effect between public capital stock and labour: above the average for manufacturing overall.

Sector analysis for the other variable factor, intermediate consumption, shows an uneven degree of substitution among the 12 manufacturing groupings. "Food products, beverages and tobacco", "Textiles, textile products, leather and footwear" and "Coke, refined petroleum products and nuclear fuel" achieved the largest savings in cost variables through lower consumption of intermediate inputs. This is all the more significant

13 Infrastructures that were financed mainly by private enterprise during the period under study showed complementarity to labour and substitution for intermediate consumption, as occurred with private capital. This will be discussed later. Boscá, Escribá and Dabán (1999) obtained similar results. given that these three sectors alone account for almost half of the gross value added generated by Colombian manufacturing, making productivity gains in these segments of manufacturing fairly powerful.

In the breakdown of private capital shadow price into the effect of decreasing (or increasing) labour costs, $L_{K P}$, and the effect of decreasing (or increasing) intermediate consumption costs, $M_{K P}$ (see the last two columns of table 2), generally speaking, private capital is complementary to labour (with the notable exceptions of "Food products, beverages and tobacco", "Wood and products of wood and cork" and "Other non-metallic mineral products") and substitutes for intermediate inputs (except in the cases of "Wood and products of wood and cork").

On the basis of the figures shown in table 2, we may conclude that the saving induced by private capital through lower consumption of intermediate materials far outweighed the increase in costs associated with additional utilization of labour. This combined effect is reflected in the magnitude and positive sign of the private capital shadow price shown in the second column of table 2 .

In short, as occurred with the magnitudes of shadow prices, the figures for the direct effects of private capital on costs associated with the two variable factors were considerably stronger than those for the direct effects of public capital. This pattern is commonly observed in the literature relating to other countries' economies.

Another interesting way to look at the effects of public capital investment and private investment in physical capital on the production of the various manufacturing sectors is to convert shadow prices into cost elasticities in relation to the two types of capital considered here, $\left(\varepsilon_{C, K G}\right.$ and $\varepsilon_{C, K P}$ ), or into output elasticities in relation to the two types of capital stock, $\left(\varepsilon_{Y, K G}\right.$ and $\left.\varepsilon_{Y, K P}\right)$. Table 3 shows measurements of these two elasticities which complement the analysis of shadow prices.

In the first column of table 3 the public capital elasticity of output, $\varepsilon_{Y, K G}$, is 0.108 , which indicates that a $1 \%$ rise in the public capital stock would increase production in Colombian manufacturing by approximately $0.11 \%$. This estimated value for $\varepsilon_{Y, K G}$ is within the range of values found in other studies conducted using the Cobb-Douglas function structure, for example, for the United States, Germany, Sweden and Spain. This particular finding leads us to question whether, as some authors have suggested, output elasticity with respect to public capital is much greater in developing than in developed countries.

Output elasticity with respect to public capital does 
vary considerably between sectors of manufacturing, however. "Wood and products of wood and cork", "Machinery and equipment, n.e.c." and "Electrical and optical equipment" showed the greatest impacts from public capital investment. Although the types of infrastructure studied here - telecommunications, transport, energy and hydraulics — also satisfy the needs of individuals (through communications, transport, energy, access to drinking water and so forth) and are used by firms across the rest of the production sector, the results suggest that the long-maturing investments made were not the most suited to stimulating manufacturing production: these activities did increase their share in Colombia's manufacturing output between 1990 and 2005, but still represented less than $6 \%$ at the end of the period. Conversely, "Food products, beverages and tobacco", "Chemicals and chemical products" and "Textiles, textile products, leather and footwear", which accounted for over half of manufacturing output in that period, lost share of that output and registered below-average output elasticities with respect to public capital. ${ }^{14}$

Output elasticity in relation to private capital (second column of table 3, 0.068) was smaller than for public capital $(0.1084)$, indicating that private capital had a lesser effect on productivity. $\varepsilon_{Y, K P}$ also varied considerably between industries.

Another interesting perspective for analysis is cost elasticity with respect to public and private capital. $^{15}$ The last two columns of table 3 show the values obtained for these elasticities. The first point to mention is that the cost elasticity in relation to private capital, $\varepsilon_{C, K P}$ (where the influence is through the cost of capital utilization) is positive, i.e. production costs are higher where private capital is used more intensively in manufacturing. This elasticity is expected to be negative, not positive as here.

This occurs because the decline in variable costs attributable to private capital investment (reflected in the positive value of the shadow price) is offset by the higher costs reflected in the payments businesses must make for additional units of private fixed capital. This pattern may be attributed to the very high cost of private capital utilization throughout the period under study and

\footnotetext{
${ }^{14}$ It should be recalled that the study period consists of two stages. In the first, the decade of the 1990s, the value of production of Colombian manufacturing overall hardly grew at all. By contrast, in the second stage there were two growth spurts in 2000 and 2003, each followed by bienniums of more moderate growth.

15 As well as yielding shadow prices, the other great advantage of using duality theory is that it enables derivation of cost elasticities with respect to public and private capital.
}

especially from 1994 onwards, which far exceeded the shadow price in the 12 manufacturing groupings for all the years, and even more so in the last 10 years of the sample. Underlying the high cost of private capital utilization was undoubtedly the interest rate, one of the variables that most influences the cost of using private capital. From 1990 to 1999 the average annual borrowing rate was $29.24 \%$ and the average annual lending rate, $39.72 \% .{ }^{16}$

A simple simulation exercise using an interest rate similar to that observed in developed countries in those years yields results more consistent with expected values and the shadow prices of private capital in that case were higher than the cost of capital utilization and, of course, cost elasticity with respect to private capital, $\varepsilon_{C, K P}$, was negative as would be expected. ${ }^{17}$

According to Botero, Hassan and Palacio (2007), the real interest rate exerts the most important effect in explaining the decline in the cost of private capital utilization in Colombia between 2001 and 2005: in fact it explains that decline almost entirely. From this work we may also conclude that falling interest rates are the main determinant of rising investment in fixed assets in Colombia in the latter years of the period under study, given the strong negative correlation between the cost of capital utilization and private capital investment.

The pattern of cost elasticity with respect to public capital was more in keeping with expectations and was negative across all sectors, especially in "Food products, beverages and tobacco"; "Wood and products of wood and cork"; "Chemicals and chemical products"; and "Machinery and equipment, n.e.c.". On average, Colombian manufacturing showed an $\varepsilon_{C, K G}$ of $(-0.1486)$, indicating that a $1 \%$ increase in public

\footnotetext{
16 Works by Moreno, López-Bazo and Artís (2002), among others, use the discount rate on government bonds of more than two years maturity as a reference interest rate for constructing the series of private capital utilization cost (or the price of capital). Reliable data could not be found to complete the 1990-2005 period for the case of Colombia, however, since the official statistics published by the Central Bank of Colombia include this variable only from 1999 onwards.

17 The simulation exercise performed with interest rates for European countries showed that in Colombia greater macroeconomic stability, as reflected in lower interest rates than those recorded between 1990 and 2005, would have enabled, ceteris paribus, lower private capital utilization costs and, therefore, shadow prices for private capital higher than its usage cost, as well as negative cost elasticity with respect to private capital as would be expected. This suggests that sustained growth in manufacturing production and in Colombia's GDP more broadly, requires not only adequate endowments of human, technological, private and public capital, but also other conditions, such as economic institutions favourable to enterprise and macroeconomic stability to underpin relatively moderate rates of inflation and interest to avoid jeopardizing decisions to invest in those stocks.
} 
capital stock reduces manufacturing companies' total costs by approximately $0.15 \%$. This may be interpreted to mean that Colombia's public capital stock is below its optimum level and that it would be socially efficient to build it up. ${ }^{18}$

In sum, the model proposed and estimated here attributes greater productivity effects $\left(\varepsilon_{Y, K G}\right)$ and cost saving effects $\left(\varepsilon_{C, K G}\right)$ to public capital investment than to private capital investment, although the shadow prices (positive in both cases) are lower for public than for private capital. In addition, generally speaking, private and public capital behave similarly in the cost structure of Colombian manufacturing, i.e. they show complementarity to labour and substitute intermediate inputs. ${ }^{19}$

As seen earlier, in the case of variable cost savings (represented by the shadow price), the sectors benefiting most from public capital investments were "Food products, beverages and tobacco", "Textiles, textile products, leather and footwear", and "Chemicals and chemical products", whereas private capital investment afforded greatest benefits to "Textiles, textile products, leather and footwear", "Pulp, paper, paper products, printing and publishing" and "Rubber and plastic products".

Comparison of the results obtained here with some earlier findings, such as those of Boscá, Escribá and Dabán (1999) for Spanish manufacturing in 1980-1993, which also estimated a Leontief generalized cost function very similar to that employed in this subsection, reveals the same relations of substitution and complementarity between fixed and variable factors, i.e. both types of capital substitute intermediate consumption and both complement employment. The shadow prices of public and private capital, though smaller than those found by Boscá, Escribá and Dabán, show the same pattern, i.e. higher in the case of private capital than public.

The findings obtained here may also be compared

\footnotetext{
18 This is especially true in regions where there is a concentration of businesses in the sectors of "Food products, beverages and tobacco"; "Wood and products of wood and cork"; "Chemicals and chemical products"; and "General-purpose machinery".

${ }_{19}$ Nevertheless, all these measurements show considerable variation between industries. The greatest savings effects from public capital investment were seen in "Foods, beverages and tobacco", "Wood and products of wood and cork", "Chemicals and chemical products" and "General-purpose machinery". The greatest savings effects from private capital investment were achieved in "Food products, beverages and tobacco", "Chemicals and chemical products", General-purpose machinery" and "Transport equipment".
}

with those of Calderón and Servén (2010a), although not so exactly, since that work concerned groups of countries rather than individual economies. It also used a different methodology to the duality theory approach and measured variables by synthetic indexes, rather than by the monetary values represented by public capital stock of infrastructure, such as those used here. ${ }^{20}$ Nevertheless, that methodology serves to contextualize the discussion on the role played by infrastructure in growth in Latin America.

These authors analyse main components to build synthetic indexes that capture data on the quantity and quality of three sectors of infrastructure: roads, telecommunications and electrical power. By regressing an augmented growth equation with the synthetic indexes of infrastructure development for a sample of 97 countries (including Latin America's largest economies) and taking as a reference period 1960-2005, the authors find that the indexes of both quantity and quality for infrastructure yield a significant positive coefficient, meaning that infrastructure contributes to economic growth. The estimates suggest that the same effects apply to Latin American countries when they are analysed separately.

On the basis of this study, Calderón and Servén (2010a) conclude that growth in Latin America could be increased by almost $2 \%$ per year on average mainly $(1.5 \%)$ by increasing the quantity of infrastructure, whereas in the Andean countries (to which group Colombia belongs) growth would benefit (by almost $3.1 \%$ per year) owing mainly $(2.4 \%)$ to a better quality of infrastructure. ${ }^{21}$

These results confirm the findings of the work described here: an increase in investment in infrastructure in Colombia (in terms of both quantity and quality) translates into a higher GDP growth rate, through more rapid growth of its manufacturing industry.

\footnotetext{
20 The dependent variable used by these authors is per capita GDP, not manufacturing production as in this work.

${ }^{21}$ In order to arrive at these outcomes, Calderón and Servén (2010a) supposed that the level of infrastructure in each Latin American country would increase to the average level observed in the middle-income countries (not including Latin America), such as those shown, for example, by Turkey and Bulgaria in terms of quantity, and Saudi Arabia and Tunisia in terms of quality.
} 


\section{III}

\section{Conclusions}

Most of the existing empirical literature on the relationship between public infrastructure and productivity gains in the manufacturing industry has taken two methodological approaches: production functions and dual cost functions. The greatest disadvantages found in the use of production functions lie in the use of very limited suppositions, either imposed by technology (usually the Cobb-Douglas function) or by the failure to consider the prices of private inputs, which can affect the intensity of their use. Other disadvantages include the imposition of constant returns and instantaneous adjustment and, therefore, failure to distinguish between the long and short terms.

By contrast, the dual approach based on cost function offers a more comprehensive estimate of the determinants of the optimizing firm's behaviour. This methodology also enables us to examine complementarity or substitution between public and private factors, as well as the marginal effects of public capital on businesses' cost structure.

This work used a model calculated under the structure of a Leontief generalized cost function (dual approach) and, generally speaking, found public capital investment to have greater productivity effects $\left(\varepsilon_{Y, K G}\right)$ and cost saving effects $\left(\varepsilon_{C, K G}\right)$ than private capital investment. Shadow prices, which were positive for both types of capital, were found to be larger for private capital, however. Private capital and public capital both were complementary to labour in Colombian manufacturing, but substituted for intermediate inputs.

All these measurements show considerable variation between industries. In the case of marginal contribution to variable cost reduction (shadow prices), the greatest positive impacts of public capital investment were seen in "Food products, beverages and tobacco", "Textiles, textile products, leather and footwear", "Chemicals and chemical products" and "Basic metals and fabricated metal products", which together account for just over half of Colombian manufacturing. The sectors befitting the most from private capital investment were "Textiles, textile products, leather and footwear", "Pulp, paper, paper products, printing and publishing", "Rubber and plastic products" and "Other non-metallic mineral products".

We may deduce that the findings on shadow prices and on the different elasticities are plausible and reflect the reality in Colombia, as well as being consistent with the results of works carried out for other economies on the magnitudes and signs of these effects.

However, the empirical evidence produced in this work leads us to question whether output elasticity with respect to public capital is considerably higher in middle- or low-income economies than in the developed countries. The shadow price of public capital allows us to infer that the major effort made since the 1990s in Colombia to expand and upgrade telecommunications, transport, energy and hydraulic infrastructures may not have been as well directed as it might have been to augment manufacturing production or did not have the desired effect during much of the period studied. This is not to disregard the fact that infrastructure also helps to meet the needs of individuals and is used by firms in other branches of economic activity not examined in this study.

It may be concluded, then, that infrastructure boosted Colombian manufacturing production, especially after 2000, but its impacts were not as great as might have been expected. This may reflect not only a lack of macroeconomic and institutional stability, but also a policy of public capital provision not entirely aligned with the reality in the country. These are issues which will certainly need to be addressed in the future although with methodologies different from those used in this article. 
ANNEX

TABLE A-1

Colombia: 12 sectors of manufacturing

$\begin{array}{ll}\text { Sector } 1 & \text { Food products, beverages and tobacco } \\ \text { Sector } 2 & \text { Textiles, textile products, leather and footwear } \\ \text { Sector } 3 & \text { Wood and products of wood and cork } \\ \text { Sector } 4 & \text { Pulp, paper, paper products, printing and publishing } \\ \text { Sector } 5 & \text { Coke, refined petroleum products and nuclear fuel } \\ \text { Sector } 6 & \text { Chemicals and chemical products } \\ \text { Sector } 7 & \text { Rubber and plastic products } \\ \text { Sector } 8 & \text { Other non-metallic mineral products } \\ \text { Sector } 9 & \text { Basic metals and fabricated metal products } \\ \text { Sector } 10 & \text { Machinery and equipment, n.e.c. } \\ \text { Sector } 11 & \text { Electrical and optical equipment } \\ \text { Sector } 12 & \text { Transport equipment }\end{array}$

Source: prepared by the authors.

(Original: Spanish)

\section{Bibliography}

Aschauer, D.A. (1989), “Is public expenditure productive?", Journal of Monetary Economics, vol. 23, No. 2, Amsterdam, Elsevier.

Boscá, J.E., J. Escribá and T. Dabán (1999), "Capital privado e infraestructuras en la producción industrial regional", Revista de economía aplicada, vol. 7, No. 21, Zaragoza, University of Zaragoza.

Botero, J.A., A. Hassan and J.F. Palacio (2007), "El costo de uso del capital y la inversión en Colombia 1990-2007”, Working Papers, No. 1, Medellín, EAFIT University.

Calderón, C. and L. Servén (2010a), "Infrastructure in Latin America", World Bank Policy Research Working Paper, No. 5317, Washington, D.C., World Bank, May.

(2010b), "Infrastructure and economic development in Sub-Saharan Africa", Journal of African Economies, vol. 19 (suppl. 1), Oxford, Oxford University Press.

DANe (National Administrative Department of Statistics) (various years), "Encuesta Anual Manufacturera", Carrera 59, No. 26-70 Interior 1 - CAN, Bogota.

(various years), "Cuentas nacionales anuales", Carrera 59, No. 26-70 Interior 1 - CAN, Bogota.

DNP (National Planning Department), "Estadísticas de inversión en infraestructuras", Infrastructure and Sustainable Energy Division [online] www.dnp.gov.co.

Mas, M., F. Pérez and E. Uriel (2005), El stock y los servicios del capital en España, (1964-2002). Nueva metodología, Bilbao, Fundación BBVA.

Moreno, R., E. López-Bazo and M. Artís (2002), "Public infrastructure and the performance of manufacturing industries: short- and long-run effects", Regional Science and Urban Economics, vol. 32, No. 1, Amsterdam, Elsevier.

Morrison, C.J. and A.E. Schwartz (1996), "State infrastructure and productive performance", The American Economic Review, vol. 86, No. 5, Nashville, Tennessee, American Economic Association.

Munnell, A.H. (1990), "Why has productivity growth declined? Productivity and public investment", New England Economic Review, Boston, Federal Reserve Bank of Boston, January-February.

Nadiri, I. and T. Mamuneas (1994), "The effects of public infrastructure and R\&D capital on the cost structure and performance of US manufacturing industries", The Review of Economics and Statistics, vol. 76, No. 1, Cambridge, Massachusetts, The MIT Press.

OECD (Organization for Economic Cooperation and Development) (2001), Measuring Capital - OECD Manual: Measurement of Capital Stocks, Consumption of Fixed Capital and Capital Services, Paris.

O’Mahony, M. and others (2008), “EUKLEMS - Linked Data: Sources and Methods", Birmingham, University of Birmingham, unpublished.

Sanaú, J. (1998), “Telecommunications infrastructure and economic growth: an analysis of Spanish manufacturing industry", Telecommunications and Socio-Economic Development, S. Macdonald and G. Madden (comps.), Amsterdam, North Holland.

Schreyer, P. and J. Dupont (2006), “OECD capital services estimates: methodology and a first set of results", Growth, Capital and New Technologies, M. Mas and P. Schreyer (comps.), Bilbao, Fundación BBVA.

Soete, L. and P. Patel (1985), "Recherche-développement, importations de technologie et croissance économique: une tentative de comparaison internationales", Revue économique, vol. 36, No. 5, Programme National Persée. 